\title{
Mental Disorders Associated with COVID-19 Related Unemployment
}

\author{
Rui Yao ${ }^{1}$ (D) Weipeng $\mathrm{Wu}^{2}$
}

Received: 13 December 2020 / Accepted: 12 April 2021 / Published online: 5 May 2021

(C) The International Society for Quality-of-Life Studies (ISQOLS) and Springer Nature B.V. 2021

\begin{abstract}
In response to the COVID-19 pandemic, restrictions on economic activities have resulted in a sharp rise of unemployment. The purpose of this research is to explore mental disorders associated with COVID-19 related unemployment using a large, nationally representative dataset, the 2020 COVID-19 Household Pulse Survey. ANOVA with post hoc tests (Tukey HSD) are utilized to reveal the mean difference of mental disorders between various employment status, as well as between reasons of unemployment. Binary logit model is used to investigate the potential effect of different reasons of unemployment on mental disorders. Individuals who were not working during the pandemic due to involuntary reasons had higher probabilities of mental disorders than those who were working and those who voluntarily separated from work. Among respondents who were not working due to COVID-19 related reasons, respondents whose employer went out of business were the most likely to experience mental disorders. Household job uncertainty in the next four weeks positively contributed to mental disorders. Government should consider measures to contain the spread of virous while keeping as many people employed as possible. Government should also consider providing adequate financial and counseling assistance to individuals who are in the greatest need for such support.
\end{abstract}

Keywords COVID-19 $\cdot$ Anxiety disorder $\cdot$ Depressive disorder $\cdot$ Mental disorders · Unemployment

Rui Yao

yaor@missouri.edu

Weipeng $\mathrm{Wu}$

ww9v5@mail.missouri.edu

1 Department of Personal Financial Planning, University of Missouri, 239B Stanley Hall, Columbia, MO 65211, USA

2 Department of Personal Financial Planning, University of Missouri, 240A Stanley Hall, Columbia, MO 65211, USA 


\section{Introduction}

The unprecedented COVID-19 pandemic has presented challenges to socio-economic determinants of mental health, such as employment hardship. In addition to being a public health crisis, the pandemic is also an economic crisis for many families as people experience employment interruptions due to reasons such as being infected with the virus or caring for family members with such infection (Faria-e-Castro 2020; Oakford and Vaghul 2020; Shierholz 2020). The United States confirmed its first case on January 21, 2020. Within 10 months, as of November 29, there are over 13 million confirmed cases with 93,219 people hospitalized, 18,198 patients in ICU, and 257,920 cumulative deaths in the United States (CDC 2020; The COVID Tracking Project 2020). Having no effective treatments or vaccinations for almost a year, all countries have uniformly relied on nonpharmaceutical methods, a.k.a. social distancing practices, to contain the spread of the virus. As a result, economic activities in the U.S. reduced sharply and quickly, making it difficult for some businesses to continue to provide employment opportunities. Many businesses have either closed permanently or have laid off or furloughed their employees in order to survive (Brynjolfsson et al. 2020; Donthu and Gustafsson 2020). A recent survey reported that $10 \%$ of workers employed before the pandemic were laid off or furloughed (Brynjolfsson et al. 2020). Only months ago, in February 2020, the United States had the lowest unemployment rate $(3.5 \%)$ in 50 years. However, the unemployment rate rose up to a record high level of $14.7 \%$ in April due to the COVID-19 pandemic (U.S. Bureau of Labor Statistics 2020). Although the labor market recovered rapidly afterwards, the unemployment rate remains high at $6.9 \%$ in October 2020.

The sudden unexpected loss of employment has led to significant diminishment of available sources of support for numerous families. Although the U.S. government made Economic Impact Payments, a.k.a. Stimulus Payments, to over 160 million families, the level of financial assistance is inadequate given the length of the pandemic and its associated economic recovery period. Since the Great Recession of 2007 to 2009 , there has been a growing body of empirical research on economic determinants of mental health such as employment hardship, including unemployment and job uncertainty. Extensive research has documented that unemployment negatively affects mental health worldwide (Audhoe et al. 2010; Dew et al. 1991; Green 2011; Jones 1991; Kim and von dem Knesebeck 2015; Lindström 2005; Linn et al. 1985; Mamun et al. 2020; Paul and Moser 2009; Tefft 2011; Worach-Kardas and Kostrzewski 2014). With high uncertainties about when the pandemic will be over and whether more businesses will be affected, it is inevitable that many feel uncertain about their jobs and experience mental disorders because of this concern. Job uncertainty, "the overall concern about the future existence of the job" (Rosenblatt and Ruvio 1996, p. 587), also has a negative effect on mental health (Browning and Heinesen 2012; Deb et al. 2011). People are more likely to develop mental health issues during a period when they experience economic uncertainty (Riumallo-Herl et al. 2014; Vandoros et al. 2019) and financial difficulties (Aneshensel et al. 1991; Fitch et al. 2011). Unemployment and job uncertainty induce financial difficulty and economic uncertainty and, therefore, can have critical effects on individuals' mental health (Kim and von dem Knesebeck 2015; Meltzer et al. 2010; Wright et al. 2016).

Mental disorders can manifest to a degree that leads to other physical diseases and risky behaviors such as substance abuse and suicide (Chesney et al. 2014; Gamm et al. 2010; 
Henriksson et al. 1993; Lönnqvist et al. 1995; Scott et al. 2008). Therefore, research on the effect of unemployment and job uncertainty on mental health during a pandemic is critically important. A few studies have examined the relationship between unemployment and mental health in an epidemic, although the different reasons for unemployment were not separated. For example, during the SARS outbreak in Hong Kong in early 2000s, mid-life women who lost jobs experienced increased levels of depressive symptoms and emotional distress ( $\mathrm{Yu}$ et al. 2005). Another study also reported distinct increases in psychological distress that were related to job uncertainty during an influenza outbreak in Australia (Taylor et al. 2008). Findings from research that investigated job uncertainty among currently employed U.S. population showed that COVID-19-induced job uncertainty is associated with greater depressive and anxiety symptoms (Wilson et al. 2020). A few studies have also studied factors that affect mental disorders during the COVID-19 pandemic, including unemployment. Studies show that unemployed individuals tend to be more vulnerable to develop the symptoms of mental disorders during the COVID-19 pandemic (Montano and Acebes 2020; Xiong et al. 2020). Based on the previous literature, we propose the following hypothesis:

H1: Involuntary unemployment and job uncertainty are positively associated with mental disorders during the COVID-19 pandemic.

An additional important aspect of the relationship between unemployment circumstances and mental health is that unemployment caused by various reasons could have different potential impacts on mental health. Previous studies have shown that the longterm unemployed have poorer mental health than the short-term unemployed (Ford et al. 2010; Mossakowski 2009; Stankunas et al. 2006). As Ford et al. (2010) documented, risk of common mental disorders (CMD) is higher in those who have been out of work for 3 years or more. Their results also showed different unemployment reasons are associated with CMD differently, such that people with physical health problems and those who cannot find a suitable job have higher risks of CMD than those not wanting/needing to work.

There are a variety of reasons for not working during the pandemic, even though these reasons may appear to have the same root-cause, coronavirus. Unlike other types of unemployment during an epidemic or pandemic, pandemic-induced unemployment could have a different impact on mental health of affected individuals. While some reasons appear to affect employment in the short run, other reasons might have longer-term consequences. For example, COVID-19 patients could return to work shortly after recovery, but employees who were laid off or whose employer's business went out of business during the pandemic may experience a long period of unemployment. Therefore, we propose the following hypothesis:

H2: Among the pandemic-induced unemployment reasons, those that potentially induce long-term unemployment have a stronger positive correlation with mental disorders than reasons that potentially lead to short-term unemployment.

Although prior literature has provided some indication of the potential effect of unemployment on mental health, our study is the first to investigate mental 
disorders related to COVID-19-induced unemployment. This study fills in the research gap in the literature of unemployment and mental health by utilizing a timely and nationally representative dataset to explore indicators of mental disorders during the pandemic, examine the association between COVID-19-induced unemployment and job uncertainty and mental disorders, and explore different associations between various unemployment reasons and mental disorder. This study also provides implications to policymakers concerning differentiated support to various populations during the pandemic.

In this study, we use data from the 2020 COVID-19 Household Pulse Survey (HPS) to examine the relationship between COVID-19-related unemployment and mental disorders. The HPS includes the two-item Generalized Anxiety Disorder scale (GAD-2) and the two-item Patient Health Questionnaire (PHQ-2) as measures for anxiety and depressive disorders, respectively. The GAD-2 and PHQ-2 efficiently identify people with anxiety and depressive disorders, and their reliability and validity have been well-documented in existing literature (Arroll et al. 2010; Löwe et al. 2005, 2010; Plummer et al. 2016; Wild et al. 2014). Within the clinical literature, anxiety and depression are classified as separate disorders and associated with different types of negative life events (Dobson 1985). Specifically, people with anxiety disorders frequently have intense, excessive and persistent worry and fear about everyday situations, while depression is a mood disorder that causes a persistent feeling of sadness and loss of interest (Mayo Clinic n.d.-a, n.d.b). Anxiety is associated with danger events, in which an unpleasant specific future crisis is fairly likely; while depression is associated with past loss events and current problems that are perceived as hard to regain or resolve (Eysenck et al. 2006; Finlay-Jones and Brown 1981; Miner and Dowd 1996). Therefore, anxiety disorder and depressive disorder are analyzed separately in this study.

We first use one-way MANOVA to test the mean differences in the overall mental disorders between respondents in different employment status during the pandemic. We also use one-way ANOVAs to analyze mean differences in anxiety and depressive disorder scales between respondents in different employment status. Next, we conduct post hoc tests (Tukey HSD) to compare the three types of employment status and different reasons for not working within multiple groups. We further apply a set of logistic regressions to investigate the association between each of the two types of unemployment and mental disorders, using the two mental disorders scales as the dependent variables. Last, we include only unemployed respondents and conducted logistic regressions to examine the association between COVID-19-related unemployment reasons and mental disorders.

Our findings show that compared to employed respondents, those who were not working for involuntary reasons were significantly more likely to be screen-positive for mental disorders. Further, compared to respondents who voluntarily separated from work, those whose employer went out of business were $70.3 \%$ to $62.1 \%$ more likely to experience anxiety and depressive disorders, highest among all respondents who did not work for pay during the past 7 days for COVID-19-related reasons, including being sick with or concerned about getting the virus. In addition, the relationship between anticipated job loss in the family and mental disorders are significantly positive, indicating the potential negative impact of job uncertainty on mental health. 


\section{Method}

\section{Data}

We use the ongoing 2020 COVID-19 Household Pulse Survey (HPS) to investigate the relationship between mental disorders and its underlying factors. The Household Pulse Survey is conducted by the U.S. Census Bureau, partnered with National Center for Health Statistics (NCHS) and multiple federal agencies (US Census Bureau 2020a). The purpose of the HPS survey is to show how the unprecedented public health and economic crisis caused by COVID-19 is affecting American families. The survey is conducted by an internet questionnaire. Participants are invited by emails and text messages. Households linked to one or more email addresses or cell phone numbers are randomly selected to participate, and one respondent from each household is selected to respond. Person weight provided by the HPS is used in this study to make sample estimates nationally representative.

Data are collected every one or two weeks beginning from April 23, 2020. Despite there are one-week or two-week collection and dissemination periods, the HPS calls these collection periods "weeks" for continuity (US Census Bureau 2020b). A total of 17 weeks of data are used in this study. The HPS data provide relevant information about the impact of coronavirus pandemic on American families, including employment status, food security, housing security, education disruptions, and physical and mental wellness.

\section{Variable Discerptions}

Table 1 shows detailed variable definitions. The dependent variables are scores of the anxiety disorder measured by the two-item Generalized Anxiety Disorder (GAD-2), and the depressive disorder evaluated using the two-item Patient Health Questionnaire (PHQ-2) (National Center for Health Statistics 2020).

The GAD-2 questions: Over the last 7 days, how often have you been bothered by the following problems ... (1) Feeling nervous, anxious, or on edge? (2) Not being able to stop or control worrying?

The PHQ-2 questions: Over the last 7 days, how often have you been bothered by ... (1) having little interest or pleasure in doing things? (2) feeling down, depressed, or hopeless?

For each item, the response options are "not at all", "several days", "more than half the days", and "nearly every day", scored as 0,1,2, and 3, respectively. Thus, the GAD-2 and PHQ-2 scores both range from 0 to 6 . A GAD-2 score of 3 or above suggests a probable anxiety disorder (Kroenke et al. 2007; Plummer et al. 2016), and a PHQ-2 score of 3 or above has been recommended for depressive disorder screening (Löwe et al. 2005).

The primary independent variables are established based on the respondents' working status. In the survey, the respondents reported whether or not they were working for pay in the last 7 days, and they were asked to choose a reason if they were not working. We classified the respondents into three groups: (1) employed; (2) voluntarily not working, if the respondent did not want to be employed at the time, or the respondent was retired; and (3) involuntarily not working, such as sick with or concerned about 
COVID-19, caring for someone with COVID-19, or employment affected by COVID19. A detailed list of reasons is provided in Table 1.

Previous studies suggest that socioeconomic status, physical health and access to medical care are significantly associated with psychological health (Ekici and Koydemir 2016; Fastame et al. 2015; Marjanovic et al. 2013; Santiago et al. 2011; Symoens et al. 2014; Worach-Kardas and Kostrzewski 2014). Limited access to medical care is another consequence of the measures used to contain the spread of the COVID-19 virus (Andrade et al. 2020; Czeisler et al. 2020). Existing health issues can become more intensive (Cai et al. 2018) and lack of access to medical care typically lead to mental disorders (Godinic et al. 2020). Therefore, we include job security, economic status, physical health and access to medical care in the logistic regressions. Job security is measured by X2 (expect family job loss, Yes = 1 and No=0). Economic status includes X3 (food sufficiency, from often not enough $=1$ to enough $=4$ ), X4 (food sufficiency confidence, from not at all $=1$ to very confident $=4$ ), X5 (paid last mortgage/rent payment on time, Yes $=1$ and No = 0), X6 (confidence of paying next month's mortgage/rent payment, from no confidence $=1$ to high confidence $=4$ ), and X7 (total family income in 2019) with eight categories ranging from less than $\$ 25,000$ to $\$ 200,000$ or more. In addition, X8 (self-reported general health status, from poor $=1$ to excellent $=5$ ) with five categories ranging from poor to excellent, $X 9$ (health insurance coverage, Yes $=1$ and No $=0$ ), X10 (no delay of medical care due to COVID, Yes $=1$ and No=0) and $\mathrm{X} 11$ (no delay of medical care due to other reasons, Yes $=1$ and No=0) are included to control for health status and access to medical care.

In this model, demographic characteristics are included as control variables. Previous studies show financial and health impacts of COVID-19 vary widely by demographic groups, such as age (Morrison and Vancouver 2000; Parker et al. 2020), gender (Alon et al. 2020; Collins et al. 2020), race (Lopez et al. 2020), education level (Liang et al. 2020), marital status (Pietromonaco and Overall 2020), and presence of children (Bayham and Fenichel 2020). Therefore, C1 (age), C2 (gender), C3 (race), C4 (education level), C5 (marital status), C6 (number of children) are used as control variables of the relationship between mental disorders and its covariates.

\section{Multivariate Tests}

In the multivariate tests, the GAD-2 and the PHQ-2 scales are used as interval variables. As the first step to investigate the relationship between employment status and mental disorders, we use a one-way MANOVA, using the two scales of mental disorders as dependent variables, to test the significance of mean differences between respondents in three employment status (working, voluntarily not working for pay, and involuntarily not working for pay). Specifically, the null hypothesis of the MANOVA tests is, employment status has no different effect on both dependent variables (anxiety and depressive disorders). To gain insight into the relationship between employment status and each scale of mental disorders, one-way ANOVAs with post hoc tests (Tukey HSD) are conducted to analyze mean differences between the three types of employment status. In addition, post hoc tests (Tukey HSD) are conducted to examine mean difference between the different reasons of not working. 
Table 1 Variable description and value

Variable Description and value

\section{Mental Disorders}

Y1: Anxiety (GAD-2)

Y2: Depression (PHQ-2)

\section{Employment Hardship}

$\mathrm{X} 1$ : Employment status

$\mathrm{X} 2$ : Expecting job loss

\section{Economic Status}

X3: Food sufficiency

X4: Food confidence

X5: Last mortgage/rent

X6: Confidence in mortgage/rent

X7: Income
In the last 7 days, (1) Feeling nervous, anxious, or on edge (2) Not being able to stop or control worrying. For each item, $0=$ not at all; $1=$ several days; $2=$ more than half the days; $3=$ nearly every day.

GAD-2 is the summed score of the two items, ranging from 0 to 6 .

In the last 7 days, (1) having little interest or pleasure in doing things (2) feeling down, depressed, or hopeless. For each item, $0=$ not at all; $1=$ several days; $2=$ more than half the days; $3=$ nearly every day.

PHQ-2 is the summed score of the two items, ranging from 0 to 6.

Main reason for not working for pay or profit is related to COVID-19 $0=$ Working; 1 = Voluntarily not working; 2 = Involuntarily not working Voluntary reasons:

1) I did not want to be employed at this time;

2) I am retired.

Involuntary reasons:

1) I am/was sick with coronavirus symptoms

2) I was concerned about getting or spreading the coronavirus

3) I am/was caring for someone with coronavirus symptoms

4) My employer experienced a reduction in business (including furlough) due to coronavirus pandemic

5) I am/was laid off due to coronavirus pandemic

6) My employer closed temporarily due to the coronavirus pandemic

7) My employer went out of business due to the coronavirus pandemic

8) I am/was caring for children not in school or daycare

9) I am/was caring for an elderly person

10) $\mathrm{I}$ am/was sick (not coronavirus related) or disabled

11) Other reasons

Expecting job loss in the family in the next 4 weeks $0=$ No; $1=$ Yes.

Food sufficiency for last 7 days

$1=$ Often not enough to eat; $2=$ Sometimes not enough to eat;

$3=$ Enough, but not always the kinds of food ( $\mathrm{I} / \mathrm{we})$ wanted to eat; $4=$ Enough of the kinds of food (I/we) wanted to eat.

Food sufficiency confidence in next four weeks

$1=$ Not at all confident; $2=$ Somewhat confident;

3 =Moderately confident; $4=$ Very confident.

Pay last month's mortgage or rent on time $0=$ No; $1=$ Yes.

Confidence in ability to pay mortgage or rent next month 1 =No confidence; 2 =Slight confidence; $3=$ Moderate confidence $4=$ High confidence.

Total family income (before taxes) in 2019

$1=$ Less than $\$ 25,000$;

$2=\$ 25,000-\$ 34,999$;

$3=\$ 35,000-\$ 49,999$;

$4=\$ 50,000-\$ 74,999$;

$5=\$ 75,000-\$ 99,999$;

$6=\$ 100,000-\$ 149,999$;

$7=\$ 150,000-\$ 199,999$; 
Table 1 (continued)

\begin{tabular}{|c|c|}
\hline Variable & Description and value \\
\hline & $8=\$ 200,000$ and above; \\
\hline \multicolumn{2}{|l|}{ Health and Access to Care } \\
\hline X8: Health & $\begin{array}{l}\text { Self-reported physical health } \\
1=\text { Poor; } 2=\text { Fair; } 3=\text { Good; } 4=\text { Very good; } 5=\text { Excellent. }\end{array}$ \\
\hline X9: Health insurance & $\begin{array}{l}\text { Health insurance coverage } \\
0=\mathrm{No} ; 1=\mathrm{Yes}\end{array}$ \\
\hline X10: No delay (COVID) & $\begin{array}{l}\text { No delayed medical care in last } 4 \text { weeks due to pandemic } \\
0=\text { delayed; } 1=\text { no delay. }\end{array}$ \\
\hline X11: No delay (other) & $\begin{array}{l}\text { No delay medical care for something not related to pandemic } \\
0=\text { delayed; } 1=\text { no delay. }\end{array}$ \\
\hline \multicolumn{2}{|l|}{ Control Variables } \\
\hline C1: Age & $\begin{array}{l}\text { Age } \\
\text { Range from } 18 \text { to } 88\end{array}$ \\
\hline C2: Gender & $\begin{array}{l}\text { Male } \\
0=\text { No; } 1=\text { Yes }\end{array}$ \\
\hline C3: Race & $\begin{array}{l}\text { Race } \\
\text { 1=White, Alone; } 2=\text { Black, Alone; } \\
3=\text { Asian, Alone; } 4=\text { Any other race alone. }\end{array}$ \\
\hline C4: Education & $\begin{array}{l}\text { Educational attainment } \\
1 \text { =high school or lower; } 2=\text { some college; associate degree; } \\
\quad 3=\text { bachelor degree; } 4=\text { graduate degree. }\end{array}$ \\
\hline C5: Martial status & $\begin{array}{l}\text { Now married } \\
0=\text { No; } 1=\text { Yes. }\end{array}$ \\
\hline C6: Number of children & $\begin{array}{l}\text { Total number of people under } 18 \text {-years-old } \\
\text { Range from } 0 \text { to } 5 \text {. }\end{array}$ \\
\hline
\end{tabular}

\section{Logistic Regressions}

We use logistic regressions to examine the relationship between mental disorders and the explanatory variables. Based on the suggested cutoff points, anxiety disorder is coded 1 if GAD- $2 \geq 3$ and 0 if otherwise and depressive disorder is coded 1 if PHQ- $2 \geq 3$ and 0 if otherwise. The results of the logistic regressions are interpreted with odds ratios and a $p$ value less than or equal 0.05 is deemed significant.

In our first set of logistic regression analyses, we include the total sample to examine the association between the two different types of unemployment and mental disorders, the primary independent variable is X1 (employment status) with three categories: working, voluntarily not working for pay (retired and do not want to work), and involuntarily not working for pay. In our second set of logistic regression analyses, to investigate the potential effect of different types of employment interruptions on mental disorders, we include only those who were not working for pay and run regressions on their reported reasons for not working. In both analyses, we include other control variables. 


\section{Results}

\section{Sample Statistics}

Table 2 shows the characteristics of the total sample of 1,576,770 respondents in this study, among whom 930,472 respondents were working during the past 7 days, while 646,298 respondents were not working (307,179 voluntarily not working for pay and 339,119 involuntarily not working for pay). The sample mean levels of mental disorders are 2.1 for anxiety disorder (GAD-2) and 1.7 for depressive disorder (PHQ2 ). About $31.9 \%$ and $25.7 \%$ respondents were screen-positive for anxiety and depressive disorders, respectively. By comparing columns 2, 3 and 4, respondents who were not working for involuntary reasons had the highest mean levels of both anxiety and depressive disorders, while those voluntarily not working had the lowest levels of disorders. For instance, the mean level of anxiety was 2.7 for respondents who were involuntarily not working, 2.0 for those were working, and 1.3 for those are voluntarily not working. About one third (31.7\%) of the total sample expected someone in their family to experience a job loss in the next 4 weeks, while over half $(54.4 \%)$ of respondents who were involuntarily not working expected a job loss in the family.

Compared to working respondents and those who were voluntarily not working, a greater portion of those who recently experienced an involuntary employment interruption reported having difficulties of affording food and paying mortgage/rent. For example, the percentage reporting often or sometimes not having enough food to eat were $7.5 \%$ for working respondents and $3.3 \%$ for voluntarily not working respondents, while a far greater percentage $(20.8 \%)$ of respondents not working for involuntary reasons reported an insufficient food issue. In addition, a higher proportion of respondents in the group whose employment was interrupted due to involuntary reasons were female, minority (Black, Asian and others), unmarried, and had lower education levels.

\section{Multivariate Test Results}

We use PROC GLM to run the one-way MANOVA and ANOVA. We conduct four multivariate tests for MANOVA. All four multivariate tests are statistically significant $(p<0.001$; Table 3), indicating that the differences between the three types of employment status exist. ANOVA with post hoc tests (Tukey HSD) reveals significant mean difference in both anxiety and depressive disorders between employment status (each $p<0.001$; Table 4). Respondents who were voluntarily not working for pay reported lowest anxiety and depressive disorders. Respondents who were involuntarily not working for pay were more likely to experience anxiety and depressive disorders than those who were working or voluntarily not working.

Table 5 reveals significant mean difference in each symptom between voluntarily not work and reasons of not working due to COVID-19 related reasons. Across all groups, the scores of mental disorders for respondents who were voluntarily separated from work were the lowest, 1.3 for anxiety disorder and 1.2 for depressive disorder. Among all respondents who were not working due to COVID-19 related reasons, those whose employer went out of business had the highest levels of mental disorders, 3.3 for anxiety disorder and 3.0 for depressive disorder. Respondents who were not working because of their employer's business reduction, however, had relatively lower levels of 
Table 2 Sample statistics

\begin{tabular}{lcccc}
\hline Employment status & All sample & Working & $\begin{array}{c}\text { Voluntarily } \\
\text { not working }\end{array}$ & $\begin{array}{c}\text { Involuntarily } \\
\text { not working }\end{array}$ \\
\hline Sample size & $N=1,576,770$ & $n=930,472$ & $n=307,179$ & $n=339,119$ \\
Percentage & $100 \%$ & $59.01 \%$ & $19.48 \%$ & $21.51 \%$
\end{tabular}

\section{Variable}

\section{Mental Health}

Y1: Anxiety

GAD $-2<3$

68.09

31.91

1.72

74.31

25.69

68.29

72.41

91.09

45.64

Yes

31.71

27.59

8.91

54.36

\section{Economic Status}

X3: Food sufficiency

Often not enough

Sometimes not enough

Enough, not want

Enough

58.11

62.77

73.20

39.37

X4: Food confidence

Not at all confident

8.96

5.77

3.48

18.74

Somewhat confident

22.80

20.50

12.89

33.55

Moderately confident

21.57

21.41

19.39

23.30

Very confident.

46.67

52.32

64.24

24.41

X5: Paid last mortgage/rent

No

14.30

11.43

5.37

23.77

Yes

85.70

88.57

94.63

76.23

X6: Confidence in paying next mortgage/rent

No confidence

9.64

Slight confidence

12.56

6.32

3.21

19.00

Moderate confidence

22.17

10.50

19.77

High confidence

55.64

20.68

4.88

27.12

X7: Total income in 2019

Less than $\$ 25,000$

15.67

62.51

17.38

34.11

$\$ 25,000$ - \$34,999

11.87

9.12

14.13

29.64

$\$ 35,000$ - $\$ 49,999$

12.68

9.68

13.05

15.41

$\$ 50,000$ - $\$ 74,999$

17.96

11.58

14.56

13.65

$\$ 75,000$ - $\$ 99,999$

13.27

18.15

19.80

16.42

$\$ 100,000$ - \$149,999

14.71

13.93

10.00

$\$ 150,000$ - \$199,999

14.84

18.36

13.47

8.74

6.63

8.76

5.34

3.23 
Table 2 (continued)

\begin{tabular}{lllll}
\hline Employment status & All sample & Working & $\begin{array}{l}\text { Voluntarily } \\
\text { not working }\end{array}$ & $\begin{array}{l}\text { Involuntarily } \\
\text { not working }\end{array}$ \\
\hline$\$ 200,000$ and above & 7.09 & 9.63 & 5.72 & 2.92
\end{tabular}

\section{Health and Access to Care}

X8: Physical health

\begin{tabular}{|c|c|c|c|c|}
\hline Poor & 3.64 & 1.62 & 3.93 & 7.49 \\
\hline Fair & 15.08 & 10.81 & 16.85 & 22.39 \\
\hline Good & 30.15 & 29.30 & 30.71 & 31.47 \\
\hline Very good & 32.97 & 36.48 & 34.22 & 25.30 \\
\hline Excellent & 17.88 & 21.58 & 13.89 & 13.09 \\
\hline \multicolumn{5}{|l|}{ X9: Health insurance coverage } \\
\hline No & 21.94 & 19.99 & 14.08 & 30.35 \\
\hline Yes & 78.06 & 80.01 & 85.92 & 69.65 \\
\hline \multicolumn{5}{|l|}{ X10: No delay of care (COVID) } \\
\hline Delayed & 38.53 & 38.29 & 32.98 & 42.68 \\
\hline No delay & 61.47 & 61.71 & 67.02 & 57.32 \\
\hline \multicolumn{5}{|l|}{ X11: No delay of care (other) } \\
\hline Delayed & 30.28 & 29.03 & 24.69 & 36.47 \\
\hline No delay & 69.72 & 70.97 & 75.31 & 63.53 \\
\hline \multicolumn{5}{|l|}{ Control Variables } \\
\hline C1: Age (mean) & 48.01 & 43.74 & 67.04 & 44.47 \\
\hline \multicolumn{5}{|l|}{ C2: Gender } \\
\hline Female & 51.63 & 47.96 & 55.42 & 56.45 \\
\hline Male & 48.37 & 52.04 & 44.58 & 43.55 \\
\hline \multicolumn{5}{|l|}{ C3: Race } \\
\hline White & 75.62 & 76.17 & 84.81 & 69.00 \\
\hline Black & 12.59 & 11.92 & 7.55 & 16.93 \\
\hline Asian & 5.62 & 6.01 & 3.87 & 5.89 \\
\hline Other & 6.17 & 5.90 & 3.77 & 8.17 \\
\hline \multicolumn{5}{|l|}{ C4: Education } \\
\hline High school or lower & 39.12 & 32.61 & 42.71 & 49.25 \\
\hline Some college & 30.50 & 30.35 & 28.71 & 32.07 \\
\hline College & 16.93 & 20.32 & 14.16 & 12.12 \\
\hline Graduate & 13.45 & 16.71 & 14.42 & 6.56 \\
\hline \multicolumn{5}{|l|}{ C5: Martial status } \\
\hline Not married & 54.35 & 56.72 & 62.09 & 44.84 \\
\hline Married & 45.65 & 43.28 & 37.91 & 55.16 \\
\hline C6: Number of children (mean) & 0.74 & 0.81 & 0.25 & 0.89 \\
\hline
\end{tabular}

Note: numbers are in percentages

mental disorders, 2.6 for anxiety disorder and 2.2 for depressive disorder. Respondents who were not working because their employer's business closed temporarily were not 
Table 3 MANOVA test for overall effect of employment status on mental disorders symptoms

\begin{tabular}{llrr}
\hline Statistic & Value & F Value & Pr $>$ F \\
\hline Wilks' Lambda & 0.935 & $23,953.9$ & $<0.001$ \\
Pillai's Trace & 0.065 & $23,641.3$ & $<0.001$ \\
Hotelling-Lawley Trace & 0.069 & $24,266.7$ & $<0.001$ \\
Roy's Greatest Root & 0.065 & $45,613.1$ & $<0.001$ \\
\hline
\end{tabular}

statistically different from those who were not working due to employer's business reduction in both anxiety and depressive disorders.

\section{Logistic Regression Results}

Association between Unemployment and Mental Disorders Table 6 shows odds ratios and associated statistical significance from our first set of logistic regression analyses, including the total sample with three categories of employment status: working, voluntarily not working for pay, and involuntarily not working for pay. These results support our first hypothesis that involuntary unemployment and job uncertainty are negatively associated with mental health during the COVID-19 pandemic after controlling for economic status, health and access to medical care, interview weeks and respondent-level demographic characteristics. Respondents who were involuntarily not working for pay were significantly more likely to be screen-positive for anxiety and depressive disorders than working respondents. For example, compared to working respondents, respondents who were involuntarily not working were $20.3 \%$ and $31.1 \%$ more likely to be screen-positive for anxiety and depressive disorders.

Table 4 ANOVA test for mean differences between various types of employment status

\begin{tabular}{lcc}
\hline & Anxiety & Depression \\
\hline Mean level of mental disorders & & 1.721 \\
Study sample & 2.063 & 1.559 \\
ES1: Working & 1.960 & 1.181 \\
ES2: Voluntarily not working & 1.331 & 2.389 \\
ES3: Involuntarily not working & 2.735 & $36,501.4$ \\
ANOVA & & $<0.001$ \\
F & $40,550.4$ & $0.378^{* * *}$ \\
p value & $<0.001$ & $-0.830^{* * *}$ \\
Pairwise difference comparisons & & $-1.208^{* * *}$ \\
ES1 vs. ES2 & $0.629 * * *$ & $-0.775^{* * *}$ \\
ES1 vs. ES3 & $-1.404 * * *$ & \\
ES2 vs. ES3 & & \\
\hline
\end{tabular}

Note: $*, * *$, and $* * *$ indicate statistical significance at an alpha level of $0.05,0.01$, and 0.001 , respectively 
Table 5 Pairwise comparisons of mental disorders symptoms by reasons of not working

\begin{tabular}{llllllll}
\hline & Sample mean & 1 & 2 & 3 & 4 & 5 & 6 \\
\hline
\end{tabular}

\section{Anxiety Disorder (GAD-2)}

1. Voluntarily not working

2. Sick with or concerned about COVID

3. Caring someone with COVID

4. Employer's business reduction due to COVID

5. Laid off due to COVID

6. Employer's business closed temporarily due to COVID

7. Employer went out of business due to COVID

Depressive Disorder (PHQ-2)

1. Voluntarily not working

2. Sick with or concerned about COVID

3. Caring someone with COVID

4. Employer's business reduction due to COVID

5. Laid off due to COVID

6. Employer's business closed temporarily due to COVID

7. Employer went out of business due to COVID
1.331

3.045

3.100

2.570

2.957

2.589

3.264

1.181

2.733

2.729

2.230

2.578

2.254

2.985

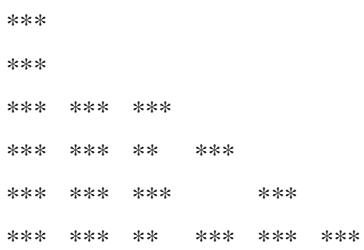

*** $* * * * * * * * * \quad * * * \quad * * *$

Note: Sample size $=482,964 ; * * *$, and $* * *$ indicate statistical significance at an alpha level of $0.05,0.01$, and 0.001 , respectively

Table 7 presents odds ratios from our second set of logistic regression analysis, including only families with a respondent who was not working for pay. Different reasons for employment interruption are the main independent variables. Other independent variables are the same as those included in the first set of regression analyses. Since the patterns of the odds ratio of those variables on mental disorders are similar to those shown in Table 6, we include only the results for the variables of interest in this table. The correlation between the pandemic-induced unemployment and mental disorders is generally high but varies by different reasons. The results support our second hypothesis that, among the pandemic-induced unemployment reasons, those that potentially induce long-term unemployment have a stronger positive correlation with mental disorders than reasons that potentially lead to short-term unemployment. Specifically, employees who were laid off and those whose employer went out of business due to COVID-19 considerably had greater odds of mental disorders than those whose reasons for not working was being sick with or concerned about the COVID-19. Compared to those who were voluntarily not working, respondents who were sick with or concerned about COVID-19 were $51.3 \%$ and $42.3 \%$ more likely to be screenpositive for anxiety and depressive disorders, respectively. More significantly, compared with respondents who were voluntarily not working, those whose employer went out of business were $70.3 \%$ to $62.1 \%$ more likely to be screen-positive for anxiety and depressive disorders, highest among all respondents who did not work for pay during the past 7 days for COVID-19-related reasons, including being sick with or concerned about getting the virus. Different from reasons that would likely lead to short-term unemployment (e.g. being sick with or concerned about getting the virus), reasons such 
Table 6 Odds ratio from logistic regressions of mental disorders measures

\begin{tabular}{lll}
\hline Variable & Model 1 & Model 2 \\
& Anxiety Disorder & Depressive Disorder
\end{tabular}

X1: Employment status (ref. = working)

Voluntarily not working

$0.948 * * *$

$1.123 * * *$

Involuntarily not working

$1.203 * * *$

$1.311 * * *$

$\mathrm{X} 2$ : Expecting job loss in the family

$1.371 * * *$

$1.240 * * *$

\section{Economic Status}

X3: Food sufficiency

$0.725^{* * * *}$

0.696 ***

$\mathrm{X} 4$ : Food confidence

$0.765 * * *$

$0.781 * * *$

X5: Last mortgage/rent paid on time

$0.965 * * *$

$0.974 * *$

X6: Confidence in paying mortgage/rent

$0.861^{* * * *}$

$0.870 * * *$

X7: Total 2019 income (ref. = less than $\$ 25,000$ )

$\$ 25,000-\$ 34,999$
$\$ 35,000-\$ 49,999$
$\$ 50,000-\$ 74,999$
$\$ 75,000-\$ 99,999$
$\$ 100,000-\$ 149,999$
$\$ 150,000-\$ 199,999$
$\$ 200,000$ and above

0.991

0.985

1.013

1.006

$1.063 * * *$

$1.020 *$

$1.066^{* * * *}$

0.987

$1.077 * * *$

$0.961 * * *$

$1.098 * * *$

$0.955 * * *$

$1.112 * * *$

$0.905 * * *$

\section{Health and Access to Care}

X8: Health

$0.779 * * *$

$0.743 * * *$

X9: Health insurance

0.992

$0.940 * * *$

X10: No delay (COVID)

$0.614 * * *$

$0.681 * * *$

X11: No delay (other)

$0.716 * * *$

$0.706^{* * *}$

\section{Control Variables}

C1: Age

$0.976^{* * * *}$

$0.979 * * *$

C2: Male

$0.707 * * *$

$0.935 * * *$

C3: Race (ref. = White)

Black

$1.103 * * *$

$1.048 * * *$

Asian

$0.693 * * *$

$0.748 * * *$

Other

$0.710 * * *$

$0.887 * * *$

C4: Education (ref. = high school or lower)

Some college

$1.156 * * *$

$1.082 * * *$

College

$1.320 * * *$

$1.087 * * *$

Graduate degree

$1.405 * * *$

$1.049 * * *$

C5: Married

$0.864 * * *$

$0.755 * * *$

C6: Number of children

$0.916^{* * * *}$

$0.865^{* * *}$

Week $($ ref. = week 1: Apr 23 - May 5

Week 2: May 7 - May 12

$0.917 * * *$

1.017

Week 3: May 14 - May 19

$0.965^{* * *}$

$1.047 * *$

Week 4: May 21 - May 26

$0.932 * * *$

$1.046 * *$

Week 5: May 28 - Jun 2

0.994 
Table 6 (continued)

\begin{tabular}{|c|c|c|}
\hline Variable & $\begin{array}{l}\text { Model } 1 \\
\text { Anxiety Disorder }\end{array}$ & $\begin{array}{l}\text { Model } 2 \\
\text { Depressive Disorder }\end{array}$ \\
\hline Week 6: Jun 4 - Jun 9 & $1.067 * * *$ & $1.094 * * *$ \\
\hline Week 7: Jun 11 - Jun 16 & $1.102 * * *$ & $1.079 * * *$ \\
\hline Week 8: Jun 18 - Jun 23 & $1.092 * * *$ & $1.096 * * *$ \\
\hline Week 9: Jun 25 - Jun 30 & $1.122 * * *$ & $1.138 * * *$ \\
\hline Week 10: Jul 2 - Jul 7 & $1.160 * * *$ & $1.148^{* * *}$ \\
\hline Week 11: Jul 9 - Jul 14 & $1.221 * * *$ & $1.179 * * *$ \\
\hline Week 12: Jul 16 - Jul 21 & $1.270^{* * * *}$ & $1.249 * * *$ \\
\hline Week 13: Aug 19 - Aug 31 & $1.236^{* * *}$ & $1.206^{* * * *}$ \\
\hline Week 14: Sep 2 - Sep 14 & $1.228 * * *$ & $1.202 * * *$ \\
\hline Week 15: Sep 16 - Sep 28 & $1.342 * * *$ & $1.295 * * *$ \\
\hline Week 16: Sep 30 - Oct 12 & $1.362^{* * * *}$ & $1.311 * * *$ \\
\hline Week 17: Oct $14-$ Oct 26 & $1.404 * * *$ & $1.359 * * *$ \\
\hline
\end{tabular}

Note: Sample size $=1,576,770$; total sample. $*$, **, and $* * *$ indicate statistical significance at an alpha level of $0.05,0.01$, and 0.001 , respectively

as employer being out of business and being laid off could result in a long-term unemployment if the virus spread is not effectively contained. Our results suggest that people are more worried about the potential of long-term unemployment than temporarily not working due to sickness.

Association of Other Variables and Mental Disorders Compared to respondents who did not expect family job loss, those who were expecting job loss within the family in the next four weeks were $37.1 \%$ more likely to be screen-positive for anxiety disorder (Table 6). Similar relationships also exist between employment status and depressive disorder. Respondents facing involuntary employment interruption were $24.0 \%$ more

Table 7 Odds ratio from logistic regressions of mental disorders by reasons of not working for pay

\begin{tabular}{lll}
\hline Variable & $\begin{array}{l}\text { Model 1 } \\
\text { Anxiety Disorder }\end{array}$ & $\begin{array}{l}\text { Model 2 } \\
\text { Depressive Disorder }\end{array}$ \\
\hline Reasons for not working (ref. = voluntarily not working) & & \\
Sick with or concerned about COVID & $1.513 * * *$ & $1.423 * * *$ \\
Caring someone with COVID & $1.735^{* * *}$ & $1.448^{* * *}$ \\
Employer's business reduction due to COVID & $1.381^{* * *}$ & $1.274^{* * *}$ \\
Laid off due to COVID & $1.538^{* * *}$ & $1.444^{* * *}$ \\
Employer's business closed temporarily due to COVID & $1.302^{* * *}$ & $1.225^{* * *}$ \\
Employer went out of business due to COVID & $1.703 * * *$ & $1.621^{* * *}$ \\
\hline
\end{tabular}

Note: Sample size $=646,298$; sample including respondents not working for pay; $*$, $* *$, and $* * *$ indicate statistical significance at an alpha level of $0.05,0.01$, and 0.001 , respectively 
likely to be screen-positive for depressive disorder than those who were working for pay in the past 7 days.

Respondents with higher food and housing security were less likely to be screenpositive for mental disorders. For example, in Model 1, respondents with a higher food security level were $27.5 \%$ less likely to be screen-positive for anxiety disorder. Also, respondents who were confident about future mortgage/rent expenses were $13.9 \%$ less likely to be screen-positive for anxiety disorder than those with low confidence.

The significant correlations between pre-COVID-19 income level and the two mental disorder measures deserve special attention. Conflicting with the prior literature (Dijkstra-Kersten et al. 2015; Michael et al. 2007), our results show that anxiety disorder was positively correlated with income during the pandemic. The odds of anxiety disorder increased gradually with income, with respondents in the highest income level (over $\$ 200,000$ ) being $11.2 \%$ more likely to be screen-positive for anxiety disorder than those whose income was less than $\$ 25,000$. This finding is consistent with a study conducted during the pandemic by The Recovery Village, that anxiety increased with income (LaNeve 2020). This positive correlation can be explained by the enormous uncertainty caused by the COVID-19 pandemic. Prior literature established that anxiety is a future-oriented mood state, in which individuals anticipate a highly likely unpleasant crisis (Eysenck et al. 2006; Finlay-Jones and Brown 1981) and high-income individuals have a stronger expectation for a constant availability of resources (Wanberg et al. 2020). During the pandemic, the expectation of constantly available resources is seriously challenged. Therefore, it is plausible that individuals with high incomes experienced greater declines in mental well-being due to the anticipation of crisis and exhibited more anxiety symptoms. Consistent with findings in prior literature, our results show that depressive disorder has a negative relationship with income. Respondents in the highest income level were $9.5 \%$ less likely to be screen-positive for depressive disorder than those in the lowest income level. Since depression is associated with past loss events or current problems, the pandemic deepens the financial problems that low-income individuals have been facing, which can lead to deterioration in their mental health and generate depressive disorder during the COVID-19 pandemic (Eysenck et al. 2006; Finlay-Jones and Brown 1981; HertzPalmor et al. 2020; Miner and Dowd 1996; Pieh et al. 2020).

Better physical health condition and access to medical care significantly reduced the odds of screen positive for mental disorders. In particular, compared to respondents whose medical care was delayed due to COVID-19, those who did not have delayed medical care were $38.6 \%, 31.9 \%$ less likely to be screen-positive for anxiety and depressive disorders, respectively. Being older, male, and married as well as having more children were negatively associated with mental disorders, whereas a higher level of education was positively associated with higher possibility of mental disorders. Notably, in Model 1, compared to respondents whose highest education level were high school or lower, those with a graduate degree were $40.5 \%$ more likely to be screenpositive for anxiety disorder. Individuals with higher education levels may experience greater declines in mental well-being due to the pandemic-induced career interruption. Compared with Whites, Blacks tended to have possibility of mental disorder, while Asian and other races were less likely to be screen-positive for mental disorders. It is also worth noting that the average odds of mental disorders changed over time, which was possibly correlated with the number of daily cases of COVID-19 (Fig. 1). 


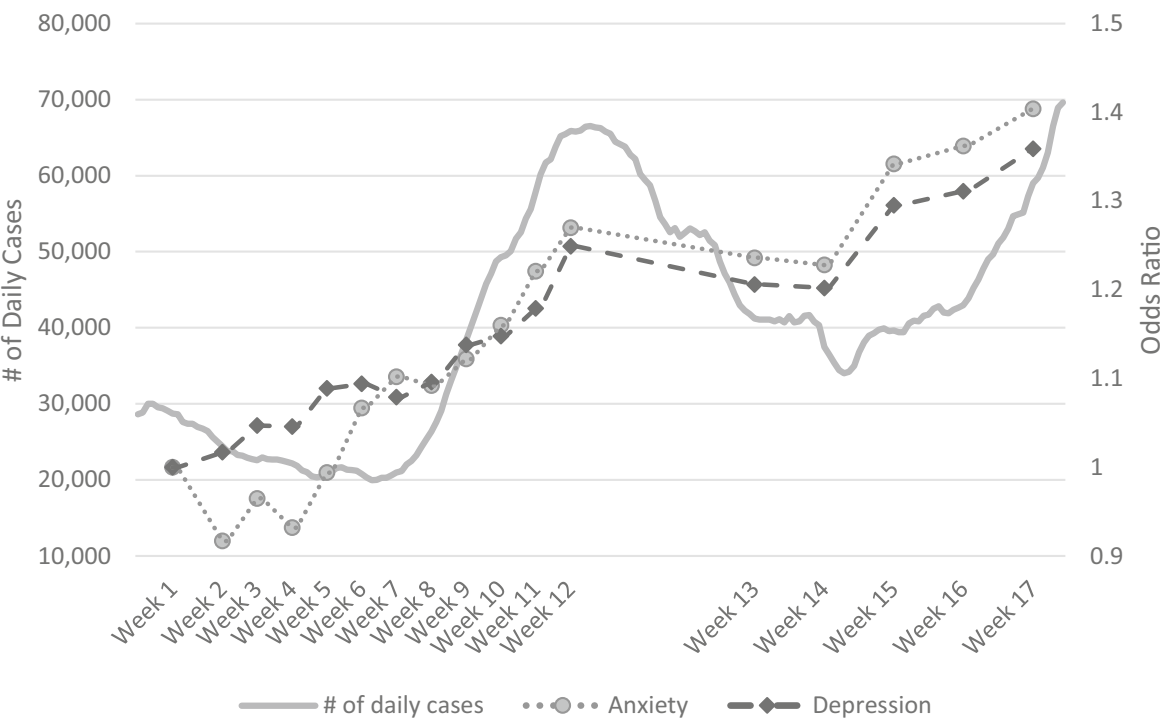

Fig. 1 Number of daily COVID-19 cases and odds ratio of week to anxiety and depression

\section{Discussion}

Mental disorders can lead to other physical diseases and risky behaviors, especially during a pandemic when disorders levels are likely to be higher than usual. Our sample of unemployed individuals exhibited prevalent mental disorders during the pandemic. Our findings resonate with prior research that studies the relationship between employment hardship and mental disorders in that currently unemployed individuals who either recently experienced a job loss or anticipate a job loss in the family in the near future are more likely to be screen-positive for mental disorders.

Our study is the first to investigate mental disorders that is associated with COVID19-related involuntary unemployment and compare its severity with mental disorders across various pandemic-induced reasons of unemployment, highlighting the influence of the pandemic on people's mental health. Our findings expand the body of knowledge on the potential effect of unemployment and mental disorders by calling attention to pandemic-induced involuntary unemployment due to its stronger association with mental disorders. After controlling for demographic characteristics, economic status, health and access to medical care, involuntary unemployment has a significantly higher degree of potential effect on mental health than voluntarily work separation. Further, among the COVID-19-related reasons, those that potentially induce long-term unemployment appeared to have hit mental health the hardest.

Our findings resonate with prior research in that job uncertainty increases mental disorders. After accounting for financial status and other employment situations in the family, expecting job losses in the next four weeks contributes to greater mental disorders symptoms. Job losses are directly related to loss of labor income, a major family financial resource for working Americans, bringing additional financial burden 
to the family. The unique contribution of our study is that this anticipation of job loss in the family is expressed by those who are already not working for pay. Hence, it is not surprising that the differences in anxiety and depressive disorders between those who do and do not have such expectation are $37.1 \%$ and $24.0 \%$.

Since the outbreak of coronavirus in March, policymakers have tried to weigh the cost of keeping people safe against the potentially disastrous consequences of closing down the economy. Although having saved a huge number of American lives, the restrictions on economic activities have put millions of people out of work and imposed unprecedented financial hardship to those American families. On average, $40.99 \%$ people are not working for pay during the survey periods in the pandemic, among which $27.20 \%$ reported a reason directly related to the pandemic. People who lost their jobs could severely suffer from inability to afford food and housing if they don't receive adequate financial assistance. Another consequence of losing jobs is the possibility of lacking or delaying access to medical care due to the loss of employerprovided health insurance and the reduced resources to pay for health insurance premiums on their own.

The employment situations can change rapidly due to the nature of the pandemic and its associated government policies. Those currently working for pay may experience job loss and its financial consequences should the number of cases increase sharply, and the government requires stricter social distancing policies or economic lockdowns. The economic consequences have affected the viability of businesses and, consequently, reduced employment opportunities that has been proven to increase people's mental disorders. There are social safety nets designed to help unemployed individuals such as unemployment insurance and Social Security. In addition, during the pandemic, the federal government sent out stimulus checks to more than 160 million families. The stimulus checks were, however, sent out based on income taxes filed in 2019. The stimulus money was sent out very quickly and was helpful for families whose income was below a certain threshold in 2019. However, people whose employment was interrupted due to the pandemic, especially those who lost their jobs because their employer went out of business, are the ones who suffer the most from mental disorders and its associated financial consequences. Right now, their disorders may not only be related to the current disconnectedness to society and its financial consequences, but also how to reconnect during and after the pandemic, as well as whether their pre-pandemic job skills would be relevant post-pandemic.

We recommend that the government considers measures designed to help these families who are in the most sudden and greatest need for financial assistance and mental support. Furthermore, the government and the medical community should explore measures that help contain the spread of the virus and, at the same time, keep businesses running so unemployment due to reasons such as concerns about getting infected and business reduction or closure can be reduced. In addition, the government and the private sector should consider providing counseling services to those who suffer mental disorders due to pandemic-induced unemployment reasons. Last, but not the least, easily accessible mental health services are essential during the period of COVID-19 outbreak, especially for those who are in urgent need of psychological support, such as individuals who lost their jobs due to the pandemic. The long-term effect of the sudden increase in mental 
disorders during the pandemic is unknown and worth investigating by researchers who study mental disorders.

Funding This work was supported by the National Institute of Food and Agriculture [project number MOMSNC0003].

Availability of Data and Material The data used in this study are publicly available.

Code Availability SAS 9.4 was used for statistical analyses.

\section{Declarations}

Conflict of Interest We have no known conflict of interest to disclose.

\section{References}

Alon, T. M., Doepke, M., Olmstead-Rumsey, J., \& Tertilt, M. (2020). The impact of COVID-19 on gender equality (no. w26947). National Bureau of Economic Research.

Andrade, C., \& others. (2020). COVID-19 and lockdown: Delayed effects on health. Indian Journal of Psychiatry, 62(3), 247-249.

Aneshensel, C. S., Rutter, C. M., \& Lachenbruch, P. A. (1991). Social structure, stress, and mental health: Competing conceptual and analytic models. American Sociological Review, 56(2), 166-178.

Arroll, B., Goodyear-Smith, F., Crengle, S., Gunn, J., Kerse, N., Fishman, T., Falloon, K., \& Hatcher, S. (2010). Validation of PHQ-2 and PHQ-9 to screen for major depression in the primary care population. The annals of family medicine, 8(4), 348-353.

Audhoe, S. S., Hoving, J. L., Sluiter, J. K., \& Frings-Dresen, M. H. W. (2010). Vocational interventions for unemployed: Effects on work participation and mental distress. A systematic review. Journal of Occupational Rehabilitation, 20(1), 1-13.

Bayham, J., \& Fenichel, E. P. (2020). Impact of school closures for COVID-19 on the US health-care workforce and net mortality: A modelling study. The Lancet Public Health, 5(5), 271-278.

Browning, M., \& Heinesen, E. (2012). Effect of job loss due to plant closure on mortality and hospitalization. Journal of Health Economics, 31(4), 599-616.

Brynjolfsson, E., Horton, J. J., Ozimek, A., Rock, D., Sharma, G., \& TuYe, H.-Y. (2020). COVID-19 and remote work: an early look at US data (no. w27344). National Bureau of Economic Research.

Cai, R. Y., Richdale, A. L., Dissanayake, C., \& Uljarević, M. (2018). Brief report: Inter-relationship between emotion regulation, intolerance of uncertainty, anxiety, and depression in youth with autism spectrum disorder. Journal of Autism and Developmental Disorders, 48(1), 316-325.

CDC. (2020). CDC COVID Data Tracker. Coronavirus Disease 2019 (COVID-19). https://covid.cdc.gov/ covid-data-tracker/\#cases_casesinlast7days. Accessed 4 November 2020.

Chesney, E., Goodwin, G. M., \& Fazel, S. (2014). Risks of all-cause and suicide mortality in mental disorders: A meta-review. World Psychiatry, 13(2), 153-160.

Collins, C., Landivar, L. C., Ruppanner, L., \& Scarborough, W. J. (2020). COVID-19 and the gender gap in work hours. Gender, Work \& Organization. Wiley Online Library. https://onlinelibrary.wiley.com/doi/ abs/10.1111/gwao.12506, COVID-19 and the gender gap in work hours

Czeisler, M. É., Marynak, K., Clarke, K. E. N., Salah, Z., Shakya, I., Thierry, J. M., Ali, N., McMillan, H., Wiley, J. F., Weaver, M. D., Czeisler, C. A., Rajaratnam, S. M. W., \& Howard, M. E. (2020). Delay or avoidance of medical care because of COVID-19-related concerns_-United States, June 2020. Morbidity and Mortality Weekly Report, 69(36), 1250-1257.

Deb, P., Gallo, W. T., Ayyagari, P., Fletcher, J. M., \& Sindelar, J. L. (2011). The effect of job loss on overweight and drinking. Journal of Health Economics, 30(2), 317-327.

Dew, M. A., Penkower, L., \& Bromet, E. J. (1991). Effects of unemployment on mental health in the contemporary family. Behavior Modification, 15(4), 501-544. 
Dijkstra-Kersten, S. M. A., Biesheuvel-Leliefeld, K. E. M., van der Wouden, J. C., Penninx, B. W. J. H., \& van Marwijk, H. W. J. (2015). Associations of financial strain and income with depressive and anxiety disorders. Journal of Epidemiology and Community Health, 69(7), 660-665.

Dobson, K. S. (1985). The relationship between anxiety and depression. Clinical Psychology Review, 5(4), 307-324.

Donthu, N., \& Gustafsson, A. (2020). Effects of COVID-19 on business and research. Journal of Business Research, 117, 284-289.

Ekici, T., \& Koydemir, S. (2016). Income expectations and happiness: Evidence from British panel data. Applied Research in Quality of Life, 11(2), 539-552.

Eysenck, M., Payne, S., \& Santos, R. (2006). Anxiety and depression: Past, present, and future events. Cognition \& Emotion, 20(2), 274-294.

Faria-e-Castro, M. (2020). Back-of-the-envelope estimates of next Quarter's unemployment rate | St. Louis fed. On the Economy Blog, Federal Reserve Bank of St. Louis. https://www.stlouisfed.org/on-theeconomy/2020/march/back-envelope-estimates-next-quarters-unemployment-rate. Accessed 4 November 2020.

Fastame, M. C., Penna, M. P., \& Hitchcott, P. K. (2015). Mental health in late adulthood: What can preserve it? Applied Research in Quality of Life, 10(3), 459-471.

Finlay-Jones, R., \& Brown, G. W. (1981). Types of stressful life event and the onset of anxiety and depressive disorders. Psychological Medicine, 11(4), 803-815.

Fitch, C., Hamilton, S., Bassett, P., \& Davey, R. (2011). The relationship between personal debt and mental health: A systematic review. Mental Health Review Journal, 16(4), 153-166.

Ford, E., Clark, C., McManus, S., Harris, J., Jenkins, R., Bebbington, P., Brugha, T., Meltzer, H., \& Stansfeld, S. A. (2010). Common mental disorders, unemployment and welfare benefits in England. Public Health, 124(12), 675-681.

Gamm, L., Stone, S., \& Pittman, S. (2010). Mental health and mental disorders - A rural challenge: A literature review. Rural healthy people, 1(1), 97-114.

Godinic, D., Obrenovic, B., \& Khudaykulov, A. (2020). Effects of economic uncertainty on mental health in the COVID-19 pandemic context: Social identity disturbance, job uncertainty and psychological wellbeing model. International Journal of Management Science and Business Administration, 6(1), 61-74.

Green, F. (2011). Unpacking the misery multiplier: How employability modifies the impacts of unemployment and job insecurity on life satisfaction and mental health. Journal of Health Economics, 30(2), 265-276.

Henriksson, M. M., Aro, H. M., Marttunen, M. J., Heikkinen, M. E., Isometsa, E. T., Kuoppasalmi, K. I., et al. (1993). Mental disorders and comorbidity in suicide. American Journal of Psychiatry, 150, 935-940.

Hertz-Palmor, N., Moore, T. M., Gothelf, D., DiDomenico, G. E., Dekel, I., Greenberg, D. M., et al. (2020). Association among income loss, financial strain and depressive symptoms during COVID-19: Evidence from two longitudinal studies. Medrxiv. Cold Spring Harbor Laboratory Press. https://doi.org/10.1101/ 2020.09.15.2019533.

Jones, L. (1991). The health consequences of economic recessions. Journal of Health \& Social Policy, 3(2), $1-14$.

Kim, T. J., \& von dem Knesebeck, O. (2015). Is an insecure job better for health than having no job at all? A systematic review of studies investigating the health-related risks of both job insecurity and unemployment. BMC Public Health, 15(985), 1-9. https://doi.org/10.1186/s12889-015-2313-1.

Kroenke, K., Spitzer, R. L., Williams, J. B. W., Monahan, P. O., \& Löwe, B. (2007). Anxiety disorders in primary care: Prevalence, impairment, comorbidity, and detection. Annals of Internal Medicine, 146(5), $317-325$.

LaNeve, N. (2020). Does income level help you cope with COVID-19? | the Recovery Village drug and alcohol rehab. The Recovery Village. https:/www.therecoveryvillage.com/professionals/blog/covidmental-health-by-income-groups/. Accessed 10 February 2021.

Liang, L., Ren, H., Cao, R., Hu, Y., Qin, Z., Li, C., \& Mei, S. (2020). The effect of COVID-19 on youth mental health. Psychiatric Quarterly, 91, 841-852. https://doi.org/10.1007/s11126-020-09744-3.

Lindström, M. (2005). Psychosocial work conditions, unemployment and self-reported psychological health: A population-based study. Occupational Medicine, 55(7), 568-571.

Linn, M. W., Sandifer, R., \& Stein, S. (1985). Effects of unemployment on mental and physical health. American Journal of Public Health, 75(5), 502-506.

Lönnqvist, J. K., Henriksson, M. M., Sisometsä, E. T., Marttunen, M. J., Heikkinen, M. E., Aro, H. M., \& Kuoppasalmi, K. I. (1995). Mental disorders and suicide prevention. Psychiatry and Clinical Neurosciences, 49, 111-116. 
Lopez, M. H., Rainie, L., \& Budiman, A. (2020). Financial and health impacts of COVID-19 vary widely by race and ethnicity. Pew Research Center. https://www.pewresearch.org/fact-tank/2020/05/05/financialand-health-impacts-of-covid-19-vary-widely-by-race-and-ethnicity/. Accessed 15 November 2020.

Löwe, B., Kroenke, K., \& Gräfe, K. (2005). Detecting and monitoring depression with a two-item questionnaire (PHQ-2). Journal of Psychosomatic Research, 58(2), 163-171.

Löwe, B., Wahl, I., Rose, M., Spitzer, C., Glaesmer, H., Wingenfeld, K., Schneider, A., \& Brähler, E. (2010). A 4-item measure of depression and anxiety: Validation and standardization of the patient health Questionnaire-4 (PHQ-4) in the general population. Journal of Affective Disorders, 122(1-2), 86-95.

Mamun, M. A., Akter, S., Hossain, I., Faisal, M. T. H., Rahman, M. A., Arefin, A., Khan, I., Hossain, L., Haque, M. A., Hossain, S., Hossain, M., Sikder, M. T., Kircaburun, K., \& Griffiths, M. D. (2020). Financial threat, hardship and distress predict depression, anxiety and stress among the unemployed youths: A Bangladeshi multi-city study. Journal of Affective Disorders, 276, 1149-1158.

Marjanovic, Z., Greenglass, E. R., Fiksenbaum, L., \& Bell, C. M. (2013). Psychometric evaluation of the financial threat scale (FTS) in the context of the great recession. Journal of Economic Psychology, 36, 1-10.

Mayo Clinic. (n.d.-a-A). Anxiety disorders - symptoms and causes. https://www.mayoclinic.org/diseasesconditions/anxiety/symptoms-causes/syc-20350961. Accessed 24 February 2021.

Mayo Clinic. (n.d.-b-B). Depression (major depressive disorder) - symptoms and causes - Mayo Clinic. https:// www.mayoclinic.org/diseases-conditions/depression/symptoms-causes/syc-20356007. Accessed 24 February 2021.

Meltzer, H., Bebbington, P., Brugha, T., Jenkins, R., McManus, S., \& Stansfeld, S. (2010). Job insecurity, socio-economic circumstances and depression. Psychological Medicine, 40(8), 1401-1407.

Michael, T., Zetsche, U., \& Margraf, J. (2007). Epidemiology of anxiety disorders. Psychiatry, 6(4), $136-142$.

Miner, R. C., \& Dowd, E. T. (1996). An empirical test of the problem solving model of depression and its application to the prediction of anxiety and anger. Counselling Psychology Quarterly, 9(2), 163-176.

Montano, R. L. T., \& Acebes, K. M. L. (2020). Covid stress predicts depression, anxiety and stress symptoms of Filipino respondents. International Journal of Research in Business and Social Science (2147-4478), 9(4), 78-103.

Morrison, E. W., \& Vancouver, J. B. (2000). Within-person analysis of information seeking: The effects of perceived costs and benefits. Journal of Management, 26(1), 119-137.

Mossakowski, K. N. (2009). The influence of past unemployment duration on symptoms of depression among young women and men in the United States. American Journal of Public Health, 99(10), 1826-1832.

National Center for Health Statistics. (2020). Anxiety and depression - household pulse survey. Centers for Disease Control and Prevention. https://www.cdc.gov/nchs/covid19/pulse/mental-health.htm. .

Oakford, P., \& Vaghul, K. (2020). Nearly 75\% of Americans missing work due to COVID Aren't getting paid — JUST capital. JUST Capital. https://justcapital.com/news/our-patchwork-of-paid-sick-leave-policiesis-failing-workers/. Accessed 4 November 2020.

Parker, K., Minkin, R., \& Bennett, J. (2020). Economic fallout from COVID-19 continues to hit lower-income Americans the hardest. Pew Research Center - Social Demographic Trends. https://www. pewsocialtrends.org/2020/09/24/economic-fallout-from-covid-19-continues-to-hit-lower-incomeamericans-the-hardest/. Accessed 2 November 2020.

Paul, K. I., \& Moser, K. (2009). Unemployment impairs mental health: Meta-analyses. Journal of Vocational Behavior, 74(3), 264-282.

Pieh, C., Budimir, S., \& Probst, T. (2020). The effect of age, gender, income, work, and physical activity on mental health during coronavirus disease (COVID-19) lockdown in Austria. Journal of Psychosomatic Research, 136, 1-9.

Pietromonaco, P. R., \& Overall, N. C. (2020). Applying relationship science to evaluate how the COVID-19 pandemic may impact couples' relationships. American Psychologist. Advance online publication. https:// doi.org/10.1037/amp0000714.

Plummer, F., Manea, L., Trepel, D., \& McMillan, D. (2016). Screening for anxiety disorders with the GAD-7 and GAD-2: A systematic review and diagnostic metaanalysis. General Hospital Psychiatry, 39, $24-31$.

Riumallo-Herl, C., Basu, S., Stuckler, D., Courtin, E., \& Avendano, M. (2014). Job loss, wealth and depression during the great recession in the USA and Europe. International Journal of Epidemiology, 43(5), 1508-1517.

Rosenblatt, Z., \& Ruvio, A. (1996). A test of a multidimensional model of job insecurity: The case of Israeli teachers. Journal of Organizational Behavior, 17(S1), 587-605.

Santiago, C. D., Wadsworth, M. E., \& Stump, J. (2011). Socioeconomic status, neighborhood disadvantage, and poverty-related stress: Prospective effects on psychological syndromes among diverse low-income families. Journal of Economic Psychology, 32(2), 218-230. 
Scott, K. M., Bruffaerts, R., Simon, G. E., Alonso, J., Angermeyer, M., De Girolamo, G., et al. (2008). Obesity and mental disorders in the general population: Results from the world mental health surveys. International Journal of Obesity, 32(1), 192-200.

Shierholz, H. (2020). At least 33 million workers are being hurt by the coronavirus recession | economic policy institute. Working Economics Blog, Economic Policy Institute. https://www.epi.org/blog/at-least-33million-workers-are-being-hurt-by-the-coronavirus-recession/. Accessed 4 November 2020.

Stankunas, M., Kalediene, R., Starkuviene, S., \& Kapustinskiene, V. (2006). Duration of unemployment and depression: A cross-sectional survey in Lithuania. BMC Public Health, 6(1), 1-9.

Symoens, S., de Velde, S., Colman, E., \& Bracke, P. (2014). Divorce and the multidimensionality of men and women's mental health: The role of social-relational and socio-economic conditions. Applied Research in Quality of Life, 9(2), 197-214.

Taylor, M. R., Agho, K. E., Stevens, G. J., \& Raphael, B. (2008). Factors influencing psychological distress during a disease epidemic: Data from Australia's first outbreak of equine influenza. BMC Public Health, 8(347), 1-13. https://doi.org/10.1186/1471-2458-8-347.

Tefft, N. (2011). Insights on unemployment, unemployment insurance, and mental health. Journal of Health Economics, 30(2), 258-264.

The COVID Tracking Project. (2020). Our Data | The COVID Tracking Project. https://covidtracking.com/ data. Accessed 5 November 2020.

U.S. Bureau of Labor Statistics. (2020). Civilian unemployment rate. Graphics for Economic News Releases. https://www.bls.gov/charts/employment-situation/civilian-unemployment-rate.htm. Accessed 5 November 2020.

US Census Bureau. (2020a). Measuring Household Experiences during the Coronavirus Pandemic. https:// www.census.gov/householdpulsedata. Accessed 13 October 2020.

US Census Bureau. (2020b). Household Pulse Survey Data Tables. https://www.census.gov/programssurveys/household-pulse-survey/data.html. Accessed 10 November 2020.

Vandoros, S., Avendano, M., \& Kawachi, I. (2019). The association between economic uncertainty and suicide in the short-run. Social Science \& Medicine, 220, 403-410.

Wanberg, C. R., Csillag, B., Douglass, R. P., Zhou, L., \& Pollard, M. S. (2020). Socioeconomic status and well-being during COVID-19: A resource-based examination. Journal of Applied Psychology., 105, 1382-1396.

Wild, B., Eckl, A., Herzog, W., Niehoff, D., Lechner, S., Maatouk, I., Schellberg, D., Brenner, H., Müller, H., \& Löwe, B. (2014). Assessing generalized anxiety disorder in elderly people using the GAD-7 and GAD2 scales: Results of a validation study. The American Journal of Geriatric Psychiatry, 22(10), 1029-1038.

Wilson, J. M., Lee, J., Fitzgerald, H. N., Oosterhoff, B., Sevi, B., \& Shook, N. J. (2020). Job insecurity and financial concern during the COVID-19 pandemic are associated with worse mental health. Journal of Occupational and Environmental Medicine, 62(9), 686-691.

Worach-Kardas, H., \& Kostrzewski, S. (2014). Quality of life and health state of long-term unemployed in older production age. Applied Research in Quality of Life, 9(2), 335-353.

Wright, K. D., Lebell, M. A. N. A., \& Carleton, R. N. (2016). Intolerance of uncertainty, anxiety sensitivity, health anxiety, and anxiety disorder symptoms in youth. Journal of Anxiety Disorders, 41, 35-42.

Xiong, J., Lipsitz, O., Nasri, F., Lui, L. M. W., Gill, H., Phan, L., Chen-Li, D., Iacobucci, M., Ho, R., Majeed, A., \& McIntyre, R. S. (2020). Impact of COVID-19 pandemic on mental health in the general population: A systematic review. Journal of Affective Disorders, 277, 55-64.

Yu, H. Y. R., Ho, S. C., So, K. F. E., \& Lo, Y. L. (2005). The psychological burden experienced by Hong Kong midlife women during the SARS epidemic. Stress and Health, 21(3), 177-184.

Publisher's Note Springer Nature remains neutral with regard to jurisdictional claims in published maps and institutional affiliations. 